\title{
Texas FFA Officer Perceptions of Good Followership
}

\author{
Susan Kate Ferrell \\ Graduate Student \\ Department of Agricultural Leadership, Education, \& Communications \\ Texas A\&M University \\ College Station, TX \\ kateferrell@me.com \\ Barry L. Boyd \\ Associate Professor \\ Department of Agricultural Leadership, Education, \& Communications \\ Texas A\&M University \\ College Station, TX \\ b-boyd@tamu.edu \\ John Rayfield \\ Assistant Professor \\ Department of Agricultural Leadership, Education, \& Communications \\ Texas A\&M University \\ College Station, TX \\ jrayfield@tamu.edu
}

\begin{abstract}
This study examines Texas FFA officers' perceptions regarding the traits and characteristics that good followers possess. A content analysis of officer responses to an open-ended question found that these young leaders have a limited level of understanding of what constitutes a good follower. Furthermore, female respondents placed a greater emphasis on supporting the leader and being respectful, whereas male respondents emphasized being a team player. Males also emphasized being involved in the chapter as a desirable trait more often than females. This suggests that females are more focused on ideas that are leadersupportive and males are more action driven. Males focused more on being a team and achievement. The study demonstrates a need to emphasize followership in leader development and education curricula. Youth organizations with similar leadership development programs can better equip their future leaders with the knowledge needed to be a follower-focused leader by teaching them how to identify good followership. As youth organizations become more follower-
\end{abstract}


focused, failure to introduce followership instruction into the leadership classroom is a disservice to students.

\section{Introduction}

The study of leaders and leadership should not focus solely on the leader. The success of great leaders depends upon their ability to cultivate and develop effective followers (Lundin \& Lancaster, 1990). However, research on followership is in its infancy (Avolio, Walumbwa, \& Weber, 2009). As followers become more informed, leaders must adapt and embrace the idea of having informed followers question their leadership authority (Brown, 2003). It is important that today's leaders look to their follower's needs, for if a leader is not meeting the needs of followers, a new leader might be given authority (Brown, 2003; Ricketts, 2009). Overlooking this aspect of leadership development is something the National FFA Organization has done as they focus on promoting quality leadership. Finding out how one of the largest leader producing youth organizations views followership can help us understand the lack of focus on followership in leadership development programs, especially those focusing on youth.

\section{Purpose and Significance of the Study}

Although students involved in the FFA Organization are exposed to a broad range of leadership developing activities, studies have shown a lack of follower-focus. Mullins and Weeks (2006) found that chapter officers rated the statements: "Leaders involve their followers in the group's vision" and "They are quick to act, and show progress as it happens," as the lowest ranked practices of leaders, demonstrating the lack of a shared chapter vision. Leadership is one of the three main components the FFA Organization looks to develop in its members.

In their mission statement the FFA states that it makes a "positive difference in the lives of students by developing their potential for premier leadership, personal growth, and career success through agricultural education" (National FFA, 2012, para. 1). In addressing the FFA mission statement, Croom (2004) describes the importance of good relationships, "without a network of supportive individuals, leaders often find leading a very difficult task...leaders possess positive character traits that encourage others to seek their leadership and be comfortable with it" (p. 10). The notion of a network of supportive individuals is at the very heart of what this study seeks to address. How students involved in such a leadership organization as the FFA take into account the role of followers can only add to their development as leaders. 


\section{Review of Literature}

The term follower was adopted in the 1980s and distinctions were made between leader and manager, and follower and subordinate. Kelley's (1988) initial article on the subject, In Praise of Followers, moved the discussion of followership onto the media radar. Kelley cites several themes in the followership literature including (a) the idea that followers and leaders are roles, not people, (b) followers are active, (c) followers and leaders need to share a common purpose, and (d) the existence of a relationship between leaders and their followers. In contrast, Baker (2007) prefers the term subordinates referring to Graham's separation of the term from follower by the "degree of free choice that they exercise... subordinates followed orders because they feared punishment, had been promised rewards, or wanted to fulfill a contractual obligation" (p. 55).

In The Power of Followership, Kelley (1992) discusses the philosophical theories on why people decide to follow certain leaders rather than others; and, in general, why people may choose to be followers rather than leaders. To understand the concept of followership, it is important to define both followership and leadership. Brown (2003) defines followership as "the willingness of people to follow" (p. 68). Yukl (2010) defines leadership as "the process of influencing others to understand and agree about what needs to be done and how to do it, and the process of facilitating individual and collective efforts to accomplish shared objectives" ( p. 7). In any organization there exists the paradigm of leader and follower.

Due to the rapid growth in access to information, leaders are no longer the sole source of information for their followers. Technological advances and the Internet allow followers to form networks and be as informed as their leaders (Chaleff, 2003). Because of this, followers have greater knowledge and input on leadership, voicing their opinions, and choosing which leader to follow (Brown, 2003).

Densten and Gray (2001) defined followership by examining the follower as a learner. Focusing on a group that they consider neglected, they provided insight into the parallel relationship between teacher-student and leader-follower. Several researchers including Kelley (2008) have suggested that followers must possess leadership qualities to be successful (Chaleff, 2003; Kelley, 2008; Tannoff \& Barlow, 2002). However, research has mainly focused on the view of leader and lists behaviors to influence followers. Little research has been conducted on the followers' response to their leader (Densten \& Gray, 2001).

Avolio, Walumbwa, and Weber (2009) state that "leadership effectiveness is just as much a product of good followers as it is of good leaders" (p. 435). Kelley 
(2008) explains that because leaders do not exist in a vacuum, follower focus is needed within leaders. Being a follower has typically been viewed as a negative trait because they are thought of after the leader. In reality, followers are electing the leaders themselves (Kelley, 2008; Ricketts, 2009). The romance of leadership and how followers have been seen as more of an output of leadership rather than an input is one of concern when studying followership.

Relating to his previous work, Kelley (2008) describes five basic styles of followership - sheep, yes-people, alienated, pragmatics, and star followers. He suggests sheep are passive and allow leaders to do the thinking, whereas yespeople, although still allowing the leaders to think, are positive and ready to act while alienated followers have negative energy and are skeptical about the leader's suggestions. Pragmatics are known as people who want to maintain the status quo and will get to work once they see where the group is headed. Star followers think for themselves, are very active, and have a positive attitude.

The works of Kelley and Chaleff (Baker, 2007) are some of the first publications on followership. They are considered the main works on which the study of followership is based. The body of research on followership is still fairly limited (Avolio, Walumbwa, \& Weber, 2009), especially that related to youth and college students.

Active followership is rooted in sociology and psychology, specifically in social exchange, attribution, and small group theories. The Leader-Member Exchange Model highlighted the relationship between the follower and leader. Baker (2007) refers to Meindl et al.'s research on leadership conducted in 1985, stating “people's 'infatuation' with the romantic, heroic, mystical view of leadership might be necessary to sustain followership and to motivate individuals to respond to the organization's needs and goals" (p. 55).

Ward and Ellis (2008) found that the two most influential predictors of why youth may follow a leader are social support and social status. Youth generally enter into a followership relationship to fill a social need. If someone is popular having social status and support - others were more likely to try and have a relationship with this person as a leader. Youth desire to be independent from their parents; however, because they are not mature enough to be self-supporting emotionally, they tend to be more likely to engage in a follower relationship with other youth rather than one with adults. This helps them gain a positive selfidentity, specifically when they are associated with others with higher social support and social status (Ward \& Ellis, 2008).

Basing their research on self-determination theory, Ward, Lundberg, Ellis, and Berrett (2010) determined that adolescents liked leaders who would support 
autonomy, competency, and relatedness. This could help youth development professionals understand youth followership so they could help youth to choose better leaders to follow. When youths follow their peers, it is usually a voluntary phenomenon; therefore, understanding what attracts youth to follow is a key in their development as potential leaders and followers.

Antelo, Prilipko, and Sheridan-Pereira (2010) surveyed both followers and leaders, and found that leaders and followers disagree on perceptions of some personal attributes of the followers. This shows just how important leaderfollower communication is and how the perceptions of followership are something the leadership development field needs to address.

The purpose of the study is to identify traits of good followers as perceived by Texas FFA chapter officers. The research objectives of this study are as follows:

- To determine if FFA officers understand what good followership is by their descriptors of a good follower.

- To determine if demographic variables influence how students describe good followers.

\section{Theoretical Foundation}

Several researchers have identified traits that they believe describe good followers. Kelly (1988) notes good followers first manage themselves well. They set their own goals and decide which roles they are to take in the greater context. Next, effective followers are committed to the organization. They also build on their competencies and apply them to making the greatest impact on the organization. Lastly, effective followers exhibit courage, honesty, and credibility.

Blackshear (2004) cites eight critical characteristics of exemplary followers:

- Willing to set ego aside and function as a team player.

- Self-empowered or internal locus of control with initiative and a willingness to act.

- $\quad$ Persists or has staying power.

- Entrepreneurial in approach and spirit with a focus on taking risk to accomplish results and doing what's necessary to get things done.

- More proactive as a problem fixer rather than reactive as a problem identifier.

- $\quad$ Adaptable, flexible and capable to manage change.

- Optimistic or is positive in approach.

- Pursues continuous improvement and engages in personal development to achieve competence. (p. 9-10) 
Hurwitz and Hurwitz (2009) describe follower competencies as falling into two categories: personal management and leader support. Components of the personal management competency are:

- Communication: being informed and giving reasoning behind your actions.

- $\quad$ Attitude: stay positive; self-motivated; having the right attitude.

- Etiquette: show respect for leader and organization, trustworthy, encourage confidence in others.

- Full accountability: responsible for results; follow up; using perspective in job decisions; do the job right.

- Decisions: provide support to leader decisions; maximize value when carrying out decisions.

The leader support competency includes:

- Leader goals: supporting leader and organizational goals.

- $\quad$ Rapport: small components that make for a strong, working relationship between leader and follower (i.e., celebrate successes, remind leader of events, or follow-up without being asked).

- Culture: being an active member and participating in culture of organization.

- Style: follower adapts to leader's style; communication style, when meetings are held, etc.

Because their characteristics are clearly defined and student comments can be more easily compared, Hurwitz and Hurwitz's (2009) two categories of follower competencies were chosen as the theoretical framework of this study.

\section{Methods}

The researchers studied a convenience sample of FFA chapter officers from 11 Texas FFA chapters. These 11 chapters represented eight of the 10 FFA districts in Texas. An open-ended question was posed to the FFA chapter officers surveyed. This open-ended question was part of a larger study and was previously pilot-tested with approximately 75 current FFA members. Officers were asked, "What are the characteristics of a good follower? List all characteristics you can think of." Fifty-one officers responded to the open-ended question. 
Table 1

Characteristics of a Good Follower as Identified by TX FFA Chapter Officers (N=51)

\begin{tabular}{|c|c|c|c|c|}
\hline Female & & Male & & Total \\
\hline Listens well & 11 & Listens well & 8 & 19 \\
\hline Follows directions & 9 & Follows directions & 8 & 17 \\
\hline Respectful & 11 & Respectful & 6 & 17 \\
\hline Support leader & 12 & Support leader & 3 & 15 \\
\hline $\begin{array}{l}\text { Team player/works well with } \\
\text { others }\end{array}$ & 5 & $\begin{array}{l}\text { Team player/works well with } \\
\text { others }\end{array}$ & 8 & 13 \\
\hline Possess good moral character & 8 & Possess good moral character & 5 & 13 \\
\hline Provides input to leader/chapter & 4 & Provides input to leader/chapter & 6 & 10 \\
\hline Involved in chapter & 1 & Involved in chapter & 8 & 9 \\
\hline Holds leader accountable & 3 & Holds leader accountable & 5 & 8 \\
\hline Is responsible & 5 & Is responsible & 3 & 8 \\
\hline Hard working & 2 & Hard working & 5 & 7 \\
\hline Has qualities of a leader & 3 & Has qualities of a leader & 3 & 6 \\
\hline Continuous learner & 4 & Continuous learner & 1 & 5 \\
\hline Trustworthy & 1 & Trustworthy & 3 & 4 \\
\hline
\end{tabular}

Student responses to the open-ended question were first tabulated into a list of individual traits by one of the researchers using deductive analysis (Earlandson, Harris, Skipper, \& Allen, 1993). Each trait was coded with an M or F to denote male and female responses. The list was then reduced by combining like traits. Table 1 lists the 14 most common traits identified by the FFA officers in the study. The next step was to categorize each trait into one of Hurwitz and Hurwitz's 2009) core competencies. As discussed earlier, they describe follower competencies as falling into two categories - personal management and leader support. They clearly describe the traits within each of these two categories. These descriptors were used to categorize the followership traits described by the FFA officers. The traits and categories were then peer reviewed by an expert in the field. According to Earlandson, et al. (1993), peer debriefing helps build credibility by having an outside perspective review the hypothesis and methods. The primary researcher and peer reviewer worked together to come to consensus on each categorization. 


\section{Findings}

The 14 traits listed in Table 1 were categorized into Hurwitz and Hurwitz's (2009) competencies. Examples of the personal management competency components found include:

- Communication: Provides input to leader and chapter.

- Attitude: Possess good moral character; has qualities of a leader.

- Etiquette: Listens well; respectful.

- Full Accountability: Is responsible; hard working; continuous learner.

- Decisions: Follows directions; Support leader.

Leader support competency components found include:

- Leader Goals: Team player and works well with others; holds leader accountable.

- Rapport: Trustworthy.

- Culture: Involved in chapter.

- Style: None

\section{Conclusions}

Objective one was to determine if FFA officers understand what good followership is by their descriptors of a good follower. Comparing the FFA officers' survey responses with how researchers (Hurwitz \& Hurwitz, 2009; Kelley, 2008) describe a good follower, it may be concluded that the officers have some sense of what consists of a good follower. As a whole, officers surveyed did not strongly indicate certain characteristics of a good follower to be important. The most frequently mentioned characteristic, listens well, was only reported by 19 of the 51 respondents. Kelly (1988) notes that good followers first manage themselves well, set their own goals and decide which roles they are to take in the greater context, are committed to the organization, build on their competencies and apply them to making the greatest impact on the organization, exhibit courage, honesty, and credibility. Of Kelley's good follower attributes, FFA officers only slightly touched on the commitment to the organization and exhibiting things like courage, honesty, and credibility. At least one officer noted the idea that followers should possess some leadership qualities. Several researchers have suggested that followers must possess leadership qualities to be successful (Chaleff, 2003; Kelley, 2008; Tanoff \& Barlow, 2002). Blackshear (2004) also cites eight critical characteristics of exemplary followers, only one of which the officers' provided in their responses - willing to function as a team player.

Officers did mention a number of the Hurwitz and Hurwitz (2009) follower competencies. This demonstrates that the FFA officers surveyed had a general 
understanding of the competencies required of a good follower. Personal management and leader support were both touched on by the officers. All personal management competency components were mentioned, and all but one of the leader support competency components were mentioned. The leader support competency component of style was not mentioned by the respondents. The personal management component of full accountability had the most responses mentioned; however, is responsible, hard working, and continuous learner were among the least mentioned characteristics.

Objective two was to determine if demographic variables influence perceptions of followership. Female and male respondents both agreed that a good follower should listen well and follow directions. These two characteristics were in the top four described. Female respondents placed a greater emphasis on supporting the leader and being respectful, whereas male respondents emphasized being a team player and working well with others. Males also emphasized being involved in the chapter as a desirable trait more often than females. This suggests that females are more focused on the aspects of followership that are leader-supportive and males are more task oriented or action driven. Males want to focus more on being a team and achievement.

\section{Recommendations}

Findings from this data show a need to emphasize followership in leader development and education curricula. Followers have the power to grant leadership, so understanding the characteristics of good followers can add to the leader's efficiency (Brown, 2003). Kelley (2008) and Ricketts (2009) note the importance of followers, and how they elect the leaders. Being able to identify the types of followers, as determined by Kelley's (1988) followership theory and model of follower behavior, could greatly enhance the knowledge base which leaders receive in a leadership development experience.

Youth organizations with similar leadership development programs like the FFA can better equip their future leaders with the knowledge needed to be a followerfocused leader by teaching them how to identify good followership. As the importance of follower focus and followership becomes increasingly important, failure to introduce followership instruction into the leadership classroom is a disservice to students (Johnson, 2009).

All leadership educators, not just agricultural science teachers, could integrate followership into their teaching. FFA officers surveyed showed they had limited understanding of characteristics of a good follower. This lack of followership understanding could be improved by incorporating more follower-focus into 
leadership development by integrating Kelley's $(1988 ; 1992 ; 2008)$ theory of followership and model of follower behavior. Agricultural science teachers could include followership teaching in the classroom as part of the leadership curriculum already included in the classroom. Teaching Kelley's (1988) five basic styles of followership (i.e., sheep, yes-people, alienated, pragmatics, and star followers), could increase leaders' knowledge of how to more effectively lead the followers within their company, organization, or other context.

As research abounds on their relationship, it is undeniable that the two concepts of leadership and followership are a co-dependent relation - one cannot exist without the other (Brown, 2003; Heller \& Van Til, 1982; Hollander, 1992; Kellerman, 2007; Kelley, 1988, 1992, 2008; Pilipko, Antelo, \& Henderson, 2011; Ricketts, 2009). A good leader should be able to learn what their followers want, be a good listener, and bring about results (Brown, 2003; Ricketts, 2009).

It is recommended that additional research be conducted across other youth leadership development programs to assess youth leaders' knowledge and attitudes regarding followership as well as those of youth leadership development instructors. 


\section{References}

Antelo, A., Prilipko, E. V., \& Sheridan-Pereira, M. R. (2010). Assessing effective attributes of followers in a leadership process. Contemporary Issues In Education Research, 3(10), 1-12.

Avolio, B. J., Walumbwa, F. O., \& Weber, T. J. (2009). Leadership: Current theories, research, and future directions. The Annual Review of Psychology, 60(1), 434-436.

Baker, S. D. (2007). Followership: the theoretical foundation of a contemporary construct. Journal of Leadership \& Organizational Studies, 14(1), 50-60.

Blackshear, P. B. (2004). The followership continuum: A model for increasing organizational productivity. The Innovation Journal: The Public Sector Journal, 9(1), 1-14. Retrieved from http://www.innovation.cc/discussionpapers/blackshear_fin_v9i7.pdf

Brown, A. (2003). The new followership: A challenge for leaders. The Futurist, $37(2), 68$.

Chaleff, I. (2003). The courageous follower: Standing up to and for our leaders. ( $2^{\text {nd }}$ ed., pp. 1-218). San Francisco: Berrett-Koehler Publishers.

Croom, B. (2004, Jan-Feb). FFA members, why are we here?: Standards-based accountability in the FFA. The Agricultural Education Magazine, 76(4), 911.

Densten, I. L., \& Gray, J. H. (2001). The links between followership and the experiential learning model: followership coming of age. Journal of Leadership \& Organizational Studies, 8(1), 69-76.

Earlandson, D. A., Harris, E. L., Skipper, B. L., \& Allen, S. D. (1993). Doing naturalistic inquiry: A guide to methods. Newbury Park, CA: Sage.

Heller, T., \& Van Til, J. (1982). Leadership and followership: Some summary propositions. The Journal of Applied Behavioral Science, 18(3), 405-414. doi: $10.1177 / 002188638201800313$

Hollander, E. P. (1992). Leadership, followership, self, and others. The Leadership Quarterly, 3(1), 43-54. 
Hurwitz, M., \& Hurwitz, S. (2009). The romance of the follower - Part 2. Industrial and Commercial Training, 41(4), 199-206.

Johnson, C. (2009). Introducing followership into the leadership classroom: An integrative approach. Journal of Leadership Education, 8(2), 20-26.

Kellerman, B. (2007). What every leader needs to know about followers. Harvard Business Review, 85(12), 84-91.

Kelley, R. (2008). The Art of Followership. San Francisco: Jossey-Bass.

Kelley, R. (1992). The Power of Followership. New York: Doubleday.

Kelley, R. E. (1988). In praise of followers. Harvard Business Review, 66(6), 142-148.

Lundin, S. C., \& Lancaster, L. C. (1990). The importance of followership. The Futurist (May-June). 16-22.

Mullins, J. G., \& Weeks, W. G. (2006). Leadership behaviors exhibited by FFA chapter presidents. Journal of Agricultural Education, 47(1), 30-42. doi: 10.5032/jae.2006.01030

National FFA Organization (2012). Retrieved from https://www.ffa.org

Prilipko, E. V., Antelo, A., \& Henderson, R. L. (2011). Rainbow of followers“ attributes in a leadership process. International Journal of Management \& Information Systems, 15(2).

Ricketts, K. G. (2009). Followership. Informally published manuscript, College of Agriculture, University of Kentucky, Lexington, KY. Retrieved from http://www.ca.uky.edu/ agc/pubs/elk1/elk1205/elk1205.pdf

Tannoff, G. E., \& Barlow, C. B. (2002). Leadership and followership: Same animal, different spots? Consulting Psychology Journal: Practice and Research, 54(3), 157-165. doi: 10.1037//1061-4087.54.3.157

Ward, P. J., \& Ellis, G. D. (2008). Characteristics of Youth Leadership that Influence Adolescent Peers to Follow. Journal of Park \& Recreation Administration, 26(2), 78-94. 
Ward, P., Lundberg, N., Ellis, G., \& Berrett, K. (2010). Adolescent peer followership: A self-determination theory perspective. Journal of Park \& Recreation Administration, 28(2), 20-35.

Yukl, G. (2010). Leadership in organizations. ( ${ }^{\text {th }}$ ed.). United States: Pearson Education. 


\section{Author Biographies}

Susan Kate Ferrell earned her B.S. in Agricultural Leadership \& Development from Texas A\&M University in 2011 and her Master's of Science in Leadership Studies in 2012. She is currently a law student at St. Mary's School of Law.

Barry L. Boyd is an Associate Professor in the Department of Agricultural Leadership, Education, \& Communications (ALEC) at Texas A\&M University. He holds the Thaman Professorship in Undergraduate Teaching Excellence. Dr. Boyd earned his doctorate from Texas A\&M in 1991 with an emphasis in leadership education and instructional design and joined the ALEC faculty in 1999. He teaches courses in personal and organizational leadership development, introduction to leadership, as well as applied ethics in leadership. Dr. Boyd's research interests include teaching effectiveness in leadership education, assessment of student learning, and teaching for transformation in the classroom. $\mathrm{He}$ is a member of the Association of Leadership Educators, serving as President of the organization in 2008 and currently serves as the Editor of the Journal of Leadership Education.

John Rayfield is an assistant professor in the department of Agricultural Leadership, Education, and Communications at Texas A\&M University. Dr. Rayfield holds a bachelor's degree from Auburn University, a master's degree from the University of Georgia, and a doctorate from Texas Tech. All three degrees are in agricultural education. Dr. Rayfield served as an agricultural educator for eight years and a county extension for three years in Georgia prior to his doctoral study. Dr. Rayfield's research interests are in experiential learning (SAE) and the impact of involvement in youth organizations (FFA). 